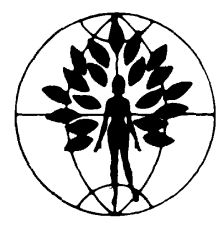

\title{
Contemporary Issues in Women's Health
}

\author{
S. Arulkumaran, M.D., Ph.D ${ }^{\mathrm{a}}$, Timothy R.B. Johnson, M.D. ${ }^{\mathrm{b}}$ \\ ${ }^{\mathrm{a}}$ Head of the Department of Obstetrics and Gynaecology, St. George's Hospital Medical School, London, UK \\ ${ }^{\mathrm{b}}$ Bates Professor of Diseases of Women and Children, Chair, Department of Obstetrics and Gynecology, Research Scientist, \\ Center for Human Growth and Development, Professor, Women's Studies, University of Michigan, Ann Arbor, Michigan, USA
}

The editors of Contemporary Issues in Women's Health solicit reporters and correspondents from throughout the world to make contributions to this section. Please feel free to e-mail or otherwise contact Dr. Timothy Johnson at trbj@umich.edu or Prof. S. Arulkumaran at s.arulkumaran@sghms. ac.uk if you have reports or stories that you would like to have included. We would be happy to attribute the items to those reporters and correpondents who give permission in their transmittal. Otherwise, we will share those reports that we think are of the greatest interest to our readership without attribution.

\section{More concern about the health of Afghanistan women}

The New York Times on October 27, 2002 reported that women continue to suffer in the current Afghan health crisis. The most comprehensive survey of medical facilities and maternal deaths every conducted in Afghanistan shows that the country's 25 million people have among the world's worst health and highest maternal mortality, described as 'a catastrophic maternal mortality rate, possibly the worst in the world'. President Hamid Karzai and Tommy G. Thompson, the United States Secretary of Health and Human Services, both voiced their concern. Other data from the maternal heath study showed that half the women of reproductive age died of complications of childbirth. In one remote province, 64 percent of deaths of reproductive age women were pregnancy-related. The study was supervised by the Environmental Committee of Physicians with the Centers for Disease Control and Prevention in the U.S. As always, education, access to primary health care, and access to service are major issues. Only 4 percent of those who died were literate, and only 30 percent had access to radio where health and hygiene principles can be disseminated.

A major concern was that the United States would forget Afghanistan, as it did after the Soviets left in 1989, as well as because of the distractions of Iraq and the war on terrorism. Mr. Thompson said that he was shocked by the challenges facing Afghanistan's women, and he therefore signed a cooperative agreement with the Afghan Health Ministry. We shall see where this new initiative leads. These issues are not new to obstetrician/gynecologists but should certainly be an ongoing part of our consciousness and our actions.

\section{Reference}

Miller J, Gall C. Women Suffer Most in Afghan Health Crisis, Experts Say. New York Times International, October 27, 2002.

\section{Nonoxynol-9 fails to prevent HIV}

According to an important article in Lancet, the effectiveness of COL-1492, a nonoxynol-9 vaginal 
gel, was tested in a randomized trial to assess effectiveness verses placebo in prevention of HIV. The study demonstrated no benefit, and nonoxynol-9 actually increased the risk of HIV infection when compared to placebo in a group of 892 female sex workers from Benin, Cote d'lvoire, South Africa and Thailand. (Adjusted relative risk $1.5 ; 95 \% \mathrm{Cl} 1.0-2.2 ; P=0.047)$. It appears that the use of nonoxynol-9 by these high risk women increases risk of HIV transmission secondary to vaginal ulcerations and other genital lesions. As articulated at the subsequent WHO/CONRAD meeting in Geneva, nonoxynol-9 should not be used to promote the prevention of HIV or sexually transmitted infections: condoms are the method of choice. As the editors mentioned (Lancet 360:962-963, 2002) 'these are not the advances that are wanted in the fight against HIV and STD.' This study at least gives us a definitive answer on nonoxynol-9, and we ought to be encouraged that this large randomized clinical trial provides definitive evidence to be used in pubic policy and patient education. Unfortunately as has become a theme in the column, this is yet another example in Obstetrics and Gynecology where new technologic interventions that were widely accepted and adopted have been shown by randomized clinical trials to have no benefit. We agree that 'Such trials, despite their cost and complexity, should be done sooner rather than later in product development'. We anticipate more reports on this topic and will make note of them in this column.

\section{References}

Van Damme L, Ramjee G, Alary M, et al. Effectiveness of COL-1492, a nonoxynol-9 vaginal gel, on HIV-1 transmission in female sex workers: A randomised controlled trial. The Lanct 2002;360:971-977.

Wilkinson D. Nonoxynol-O fails to prevent STDs, but microbicide research continues (Editorial). The Lancet 2002; 360:962-963.

www.who.int/reproductive-health/rtis/index.hrm

Salpingo-oophorectomy in the prevention of ovarian and breast cancer in high risk patients

Important studies on the role of salpingo-oophorectomy in women with BRCA1 or BRCA2 muta- tions were published in the New England Journal of Medicine in May 2002. These articles suggested that prophylactic oophorectomy in carriers of BRCA1 or BRCA2 reduced both the risk of ovarian cancer and breast cancer. These provocative studies should not lead to an immediate change in practice but, rather, to a careful consideration of the implications of this approach. For a long time, women with high risk of ovarian cancer, especially familial risks, have been undergoing this therapy. The beneficial results in terms of breast cancer mortality from the current studies were unexpected and surprising. This is an important area that we must continue to watch. It is clear that molecular genetics needs to be understood by clinical obstetrician/gynecologists and that in the very near future concepts from molecular genetics will guide our therapy and practice.

\section{References}

Kauff ND, Satagopan J, et al. Risk-reducing salpingo-oophorectomy in women with BRCA1 and BRCA2 mutation. New Engl J Med 2002;346:1609-1615.

Rebbec TR, Lynch HT, et al. Prophylactic oophorectomy in carriers of BRCA1 or BRCA2 mutations. N Engl J Med 2002;346:1616-1622.

Haber D. Prophylactic oophorectomy to reduce the risk of ovarian and breast cancer in carriers of TRCA mutations (Editorial). New Engl J Med 2002;346:16690-1661.

\section{Self breast exam: dogma disputed}

Once again, we draw our readers' attention to an article from a developing county that may affect clinical practice. There is news from China with regard to a randomized trial that is similar to our report on the Magpie Trial in a previous edition of Contemporary Issues (Int J Gynecol Obstet 78:3$5,2002)$, which showed the benefit of magnesium sulfate in the management of preeclampsia (Lancet 359:1877-1890, 2002). Now, a report from China of a well-designed, large randomized multicenter international trial shows that a common western practice, self breast examination, provides no benefit to the patients. In over 266,000 women enrolled, initial instruction in self breast exam followed by reinforcement sessions and breast self 
exam under medical supervision showed no improvement in mortality from breast cancer in the period from October 1989 to October 1991. However more non-breast lesions were diagnosed in the instruction group than the control group leading to more interventions. The conclusion was that intensive instruction in breast self examination did not reduce mortality from breast cancer. The authors suggest that breast self examination programs would be unlikely to reduce mortality from breast cancer in the absence of mammography. Women who choose to practice breast self examination should be informed of its lack of efficacy and that it may in fact increase their chance of having a benign breast biopsy. While this information is not new, the high quality of the study, so large that it will probably never be replicated, will significantly dampen enthusiasm for self breast examination. In the accompanying editorial, we are reminded that women should be encouraged to seek medical attention when they incidentally discover breast lumps but that self awareness through self examination may have an increased impact in terms of anxiety, hopeless perceptions and unnecessary and unhelpful interventions, although there may be a positive effect in the reduction in the stage of presentation of many subsequent breast cancers.

This is an interesting study and is similar to other observation in the practice of obstetrics. Many years ago, the randomized trial of routine fetal movement counting showed no benefit in large populations. Extrapolations and comparisons to other self examination practices (even to men and the recommendation for routine self testicular examination) are appropriate. This is an example of a research report that provides important results for women and carries important implications for both sexes.

\section{References}

Thomas D, Gao, DL, Ray RM, et al. Randomized trial of breast self-examination in Shanghai: Final results. J Natl Cancer Inst 2002;94:1445-1457.

Harris R, Kinsinger LS. Routinely teaching breast self-examination is dead. What does this mean? J Natl Cancer Inst 2002;94:1420-1421.

http://jncicancerspectrum.oupjournals.org/cgi/conent/ abstract/jnci;94/19/1445 